\title{
La monarquía en México: historia de un desencuentro. El liberalismo monárquico de Gutiérrez Estrada
}

\author{
Gabriela Tio Vallejo \\ EL COLEGIO de MÉxico
}

"¿Habrá quien se atreva a sostener que los pueblos han sido hechos para las formas de gobierno, y no éstas para los pueblos?"1

$\mathrm{L}$ a historiografia liberal ha presentado las ideas monárquicas como desviaciones de la evolución política de América en el siglo XIX. Así los movimientos monárquicos aparecen como expresiones de un grupo conservador, siempre minoritario, como resultado de circunstancias de política exterior, como traición o como debilidad de los protagonistas de la gesta de la independencia. Este error viene del supuesto, extendido también en la historiografia, de considerar al liberalismo, partiendo del análisis doctrinal,

1 Gutiérrez Estrada, Carta, 1840, p. 77, Biblioteca Nacional, colección Lafragua, (LAF), vol. 352. como un sistema coherente y estructurado. La hipótesis que sustenta este trabajo, es que el liberalismo fue un conjunto amplio de ideas sobre la organización política de la sociedad que, en su aplicación, revistió múltiples formas pero cuyo núcleo "esencial", lo que lo define como tal y lo distingue de otros movimientos políticos, es el jusnaturalismo, la defensa de los derechos y libertades individuales, y la idea de un pacto social como base de toda forma de gobierno. Las modalidades y extensiones de la ciudadanía y la representación, la forma misma de gobierno, el federalismo o centralismo establecidos en las constituciones, caracterizan "los liberalismos" según diferentes realidades y aspiraciones. El liberalismo que logró concretarse histórico-políticamente en Europa, lo hizo a través de monarquías constitucionales; fue un liberalismo posrevolucio- 
nario y en gran medida prevenido de los "excesos" de la revolución. En este contexto es que se pretende enmarcar el pensamiento de Gutiérrez Estrada cuyos componentes liberales demostraremos a partir de su discurso político.

Los proyectos monárquicos en América se desarrollaron en dos etapas. La primera, desde 1808 hasta la década del 20 , en que tales ideas se encontraban envueltas todavía en el problema colonial, ligadas al destino de la metrópoli y a los avatares de la guerra independentista. La segunda cuando una vez consumada la independencia, la idea de monarquía aparece como una forma política autónoma del hecho colonial.

Un ejemplo de la primera etapa es el proyecto de monarquía incaica que nació en la provincia del Río de la Plata en el momento todavía revolucionario de 1810-1825 en el contexto de la guerra con España, con el sello de una revolu. ción aún no resuelta. La acción y el espíritu del Congreso de Viena estimuló la idea de instaurar una dinastía con alguien del linaje de los incas, e incluso se tenía al candidato, un descendiente de José Gabriel Tupac-Amaru, el jefe y mártir de la rebelión. En este proyecto confluian la unión de las "razas", la reivindicación indígena frente a la conquista restableciendo en el trono a la dinastía derrocada por los españoles, el principio vigente de "restauración y legitimidad", la posibilidad de un poder centralizado que hiciera frente a las amenazas exteriores y a la disolución interna. La monarquía incaica se presentaba como una forma de legitimjdad, efectividad y unidad del ex virreinato. Pero al mismo tiempo presentaba también el elemento de discordia que condenaría el proyecto al fracaso. Al establecer su base en Perú, atentaba contra el predominio obtenido por los revolucionarios de Buenos Aires, era un nuevo traslado del poder político al antiguo centro, y las fuerzas centrípetas fueron más poderosas. ${ }^{2}$

El proyecto de Gutiérrez Estrada se inscribe en la segunda etapa, en que ya concretada la independencia se plantean las formas de organización política de los nuevos estados. La historiografía liberal tachó al monarquismo de conservador expulsándolo del pensamiento liberal americano del siglo Xxx, poniendo el acento precisamente en la vinculación de estas ideas con el mantenimiento de la situación colonial. Sin embargo, existe, en ambas fases un monarquismo independiente que no se sustenta necesariamente en un proyecto de continuidad de las estructuras coloniales, sino que se inscribe en el liberalismo. La idea monárquica en América representó para las elites dirigentes la posibilidad de concretar un orden ante la disgregación e inestabilidad que la ruptura del régimen colonial había provocado. El monarquismo fue así una opción concreta de la realidad política americana, compatible con el liberalismo, como lo fue en Europa.

EL HOMBRE Y EL MOMENTO.

LA EXPERIENCIA DE GUTIÉRREZ

DE ESTRADA EN EL GOBIERNO de MÉxICO

José María Gutiérrez de Estrada perte. necía, por nacimiento y por vínculo

${ }^{2}$ Mitre, Historla, 1927, t. II, p. 329. 
matrimonial, al sector aristocrático de la sociedad mexicana. Fue amigo íntimo de Mora, del círculo "académico" de Alamán, y puede ser considerado como el paradigma del intelectual aristócrata europeizado, fascinado por la experiencia francesa. ${ }^{3}$

Ocupó varios cargos en el Estado mexicano; en enero de 1835 aceptó la Secretaría de Estado y el Despacho de Relaciones Interiores y Exteriores, cuando gobernaba Santa Anna. Hizo votos entonces, por la consolidación de las instituciones liberales, la libertad, el orden, la seguridad y la justicia. Su decisión de abandonar esta Secretaría desencadenó un conflicto al exponer las razones verdaderas de su dimisión. Este acontecimiento mostraría su posición en la política mexicana y en sus declaraciones aparecen algunos de los rasgos de su pensamiento político.

Gutiérrez de Estrada se negó a participar en la nueva tendencia centralista que caracteriza en ese momento al gobierno de Santa Anna, considerando este cambio de rumbo como una falta al juramento hecho, al recibir el cargo, de defender la Constitución Federal del 24. Al negarse a seguir la política del gobierno de no respetarla, dice refiriéndose a su fidelidad a las leyes constitutivas de 24:

[...] cualesquiera que fuesen mis ideas propias con respecto al régimen adoptado, yo debía sacrificar mi opinión privada a las obligaciones que había ya con. traído como hombre público [...] toda la marcha que he seguido en el ministerio ha sido la que correspondía al plan que

${ }^{3}$ Hale, Liberaltsmo, 1991, p. 32. concebí desde mi ingreso, y que no era obra de mi elección libre, sino resultado preciso del deber $[\ldots]^{4}$

El pensamiento de Gutiérrez de Es. trada en este momento es francamente republicano y federal, si no por convicción, como queda implícito en estas palabras, al menos por el afán de lega. lidad constitucional de que hace gala en la Memoria del Ministerio de febrero de 1835 , al decir que el pacto social, establecido por la Constitución en 1824 , no puede ser reformulado más que por un poder equivalente al que la creó. Al hablar de las bases establecidas en 1824, en el mismo documento, dice:

[...] el sistema federal es el que la nación ha querido y debe conservar[...] el sistema que nos rige tiene mas firmes fundamentos que los que pudiera darle una fuerza mal organizada (aludiendo a la milicia cívica) y dirigida por las pasiones del momento. La federación se apoya en la voluntad nacional, muy expresamente pronunciada, y mientras esta voluntad subsiste, subsistirá también la forma de gobierno que nos hemos dado $[\ldots]^{5}$

En su defensa, Gutiérrez de Estrada propuso de relieve algo que aparecería permanentemente en sus escritos, la coherencia o consecuencia de una forma de gobierno como una forma de justicia. Al mismo tiempo que consideró que éste había sido el mérito de su ministerio, criticó la falta de homogeneidad del gobierno.

\footnotetext{
4 "Documentos, 1835, p. 16, LAF. 352.

5 Ibid., pp. 20 y 21.
} 
Me lisonjeo de poder asegurar, que en las ocurrencias de Zacatecas, del Sur y de otros varios puntos, las providencias del gobierno dictadas por el ministerio de mi cargo, han sído todas marcadas con el sello de la uniformidad con los principios referidos $[\ldots]^{6}$

A pesar de algunas expresiones que pueden parecer ambivalentes, una lectura desprejuiciada nos hace ver en este momento a un defensor del federalismo:

Mi opinión como hombre público y como individuo particular son cosas muy distintas, y deben considerarse de muy distinta manera: aun cuando yo en el corazón no fuese federalista, debía obrar en concepto de federalismo, como ministro que habia jurado la Constitución de 1824; pero debo añadir francamente, que mis opiniones particulares estaban perfectamente conformes en este punto con el cumplimiento del deber $[\ldots]^{7}$

Sin embargo, ya en este momento Gutiérrez de Estrada presentaba su preocupación por la anarquía y su deseo de un gobierno de voluntad firme que frenara los pronunciamientos: "[...] Si es un deber mantener la federación, porque así lo ha jurado el gobierno, es también un deber obligar a un estado disidente a obedecer las leyes generales, que a todos obligan igualmente $[\ldots]$.. 8 Reconoce que, desde que afirmara esto, la voluntad de los pueblos y los Ayuntamientos, de las autoridades y corporaciones ha cambiado y

\footnotetext{
${ }^{6}$ Ibid., p. 18.

7 Ibid., p. 24.

8 Ibid., p. 22.
}

que todos se pronuncian por el régimen central.

Gutiérrez explicita una concepción del poder ministerial y un supremo poder ejecutivo que se mantenga estable frente a los avatares de la vida política de la nación. Mientras que la relación entre los primeros magistrados y la nación es estrecha y directa por el voto que le deben al pueblo, los ministros como él, son nombrados por el supremo jefe del Estado y dependen de él. Su idea, que en sus escritos parte del modelo inglés, es la estabilidad de un poder superior basado en una legalidad constitucional y un sistema parlamen. tario que permita cierta flexibilidad, pero en donde los cambios o las políticas específicas sean responsabilidad de los ministros de modo tal que no afecten la cabeza del sistema político. ${ }^{9}$ Esta concepción de la responsabilidad ministerial es un rasgo interesante de su pensamiento, complementaria y compatible con la concepción de un poder supremo irresponsable que, a la manera de las monarquías europeas y brasileña, cumple un papel de figura sobre las partes, de unión y estabilidad.

La circunstancia desencadenante de la renuncia de Gutiérrez de Estrada fue la desinteligencia entre él y el gobierno en torno al pronunciamiento de Orizaba por el centralismo: el acta del pronunciamiento se recibió el 21 de mayo, él presentó su renuncia el día 25. En ella no sólo cuestionaba la actitud del gobierno de tomar este pronunciamiento como pretexto para im. pulsar el cambio de sistema, sino que

${ }_{9}$ Ibid., p. 26. 
tenía dudas sobre la idea de que los pronunciamientos expresaran verdaderamente la voluntad nacional a favor del centralismo. Pensaba que un gobierno basado en su origen en la voluntad popular, una vez establecido, debía concentrar un poder firme y no ser tan susceptible de responder a los permanentes requerimientos de cambio de los grupos que compusieran el.Estado, es un estado que fundamentalmente se identifica con la aplicación rigurosa de las leyes y el respeto de las libertades individuales. Gutiérrez de Estrada esbozaba sus expectativas respecto del devenir mexicano:

[...] ahora que todo ha vuelto a entrar en el orden legal y positivo [...] Nada probará tanto que la nación marcha hacia su prosperidad, $y$ que ha entrado en el espíritu de las instituciones que felizmente la rigen, como el que libre cada uno en sus ocupaciones respectivas, sin otro temor que el que le puedan inspirar sus acciones propias, y confiado en la protección de las leyes y en el celo y vigilancia de los magistrados, pueda creerse seguro y atender sin recelo a su mejor bienestar $[\ldots]^{10}$

El liberalismo de estas palabras es incuestionable: un orden legal y positivo que garantice las libertades individuales y la seguridad a través de la acción de los magistrados.

Después de este alejamiento conflictivo del gobierno, Gutiérrez de Estrada se marcharía a Europa donde permanecería cuatro años. Volvería a México en vísperas de la revolución encabezada, en julio de 1840 , por

${ }^{10}$ Ibid., p. 43.
Urrea y Gómez Farías contra el gobierno de Bustamante. El panorama era caótico. La revolución de julio fue particularmente violenta; al mismo tiempo, su tierra natal, Yucatán, se encontraba en una actitud secesionista; se sumaba a esto la posibilidad de la pér. dida definitiva de Texas. Según lo que él mismo expresó lo que lo impulsó a escribir la polémica carta fue el impac. to que le produjo, antes que nada, la revolución de Urrea. En una carta a Mora en julio de 1840 , se mostraba preocupado por los planes de instaurar una dictadura.

\section{EL LIBERALISMO MONÁRQUICO DF GUTIÉRREZ ESTRADA}

El 25 de agosto de 1840 , y al calor de los sucesos de julio, Gutiérrez de Estrada dirigió una carta al presidente A nastasio Bustamante "[...] sobre la necesidad de buscar en una Convención el posible remedio de los males que aquejan a la República". ${ }^{11}$

El tema clave es la ineficacia de las dos formas que revistió la república, central ismo y federalismo, para lograr la felicidad del país, del que él dedujo la inconveniencia del sistema republicano de gobierno para México. Federalismo y centralismo, son a la vez, con sus dos constituciones, causa y bande-

11 Estrictamente la carta firmada por Gutiérrez de Estrada y fechada el 25 de agosto en Tacubaya, ocupa 14 páginas en la edición de Cumplido. La introducción y las 77 páginas que continúan no formaron parte de la carta original, sino que fueron escritas por Gutiérrez para su publicación en un opúsculo, que ya completo, salió a la luz en octubre. 


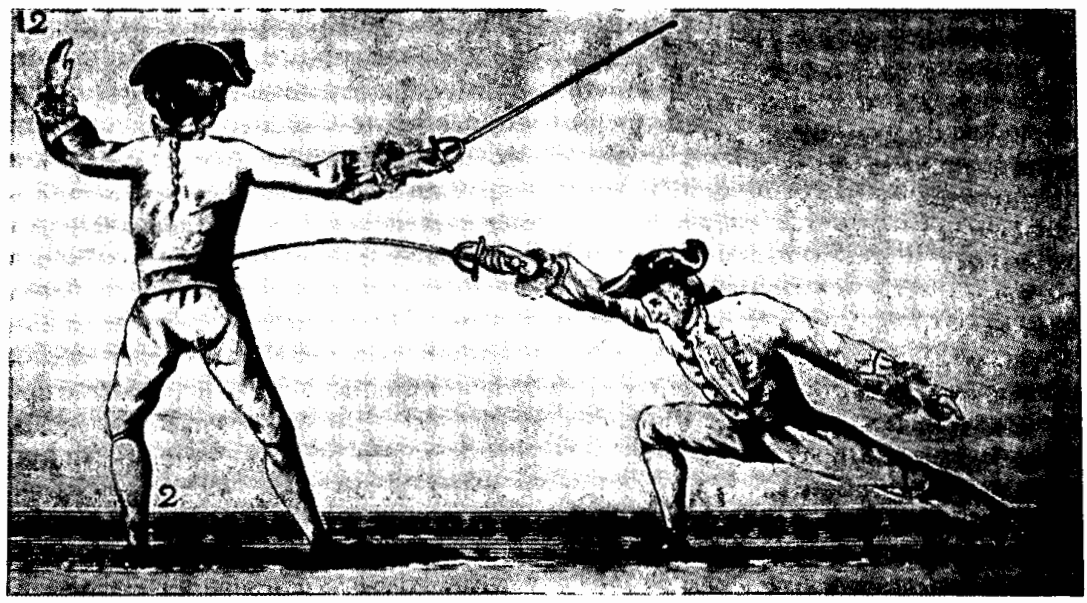

ra de la anarquía. Es necesario llamar a una Convención que elija una nueva forma de gobierno. Si la libertad puede estar presente en cualquier forma de gobierno y como la república, según ha demostrado la experiencia, no es la apropiada para México, se debe probar otro régimen de gobierno; de ello hace partir su idea monárquica. La forma monárquica de gobierno evitaría la anarquía y disolución interna y alejaría las amenazas extranjeras, léase norteamericanas.

LOS MALES DE LA REPUBIICA Y LA CAJA DE PANDORA

Gutiérrez de Estrada se presenta como un hombre que guardaba una posición externa a los partidos que se disputa. ban el poder. Fue a partir de esta perspectiva que evaluó las dos formas que revistió el proyecto republicano, expresadas en las constituciones de 1824 y 1836 como dos proyectos no viables para México. Se preguntaba cuál era el sentido de las sangrientas luchas por defender estos códigos que no eran capaces de convertirse en realidades, estos objetos de culto, en aras de los cuales se estaba sacrificando la nación.

Con respecto a la Constitución de 1824, "la caja de Pandora", le reconoció un origen legítimo fundado en la voluntad nacional que tuvo consenso durante los doce años de su aplicación; pero encontraba en ella una exageración del principio democrático que llevaría a la disolución del cuerpo social. 
La experiencia de veinte años de anarquía, de luchas sangrientas, de inestabilidad, de debilidad frente al ex. tranjero, mostraban sobradamente que las dos formas de república, tanto la federal como la central, no habían dado resultado. Este es el balance que hizo de los periodos en que una y otra constitución rigieron:

[...] República federal por espacio de doce años, durante los cuales los hombres de todos los partidos, sin excepción alguna, fueron llamados alternativamente a trabajar en favor de la nación: república central por espacio de cinco años: combatida de muerte por sus enemigos, y tibia y flojamente defendida por sus adictos, sólo ha debido su existencia a la omnipotencia de sus opositores, $y$ al horror de ver restablecida la constitución federal, bajo cuyos auspicios han ocurrido los hechos más oprobiosos de nuestra historia [...] De cuantos modos, pues, puede ser una república, la hemos experimentado democrática, oligárquica, militar, demagógica y anárquica: de manera que todos los partidos a su vez, y siempre con detrimento de la felicidad y del honor del país, han probado el sistema republicano bajo todas las formas posibles $[\ldots]^{12}$

Le negó a la Constitución de 1836 un origen popular; fue "obra de circunstancias y para determinadas personas", no gozaba de confianza y por la impopularidad de sus disposicones, provocaba resistencias inevitables $y$ poderosas, siempre se le opondría "ese grito falaz y estéril en el fondo, si 33.

12 Gutiérrez Estrada, Carta, op. cit., pp. 28 - se quiere pero siempre peligroso de "Constitución de 1824" $[\ldots]^{13} \mathrm{~A}$ la aplicación impopular de la constitución del 36 y al uso de la de 1824 como pretexto de continuas disensiones, adjudicaria él parte de la responsabilidad del problema de Texas y de Yucatán. Se definiría a sí mismo como republicano y liberal. Cuando se pronunció por la monarquía dijo:

[...] prolongada y penosa ha sido la lucha entre mi razon y mi corazón puro y sinceramente republicano, antes de persuadirme de que no es la senda que hemos seguido hasta aquí la del bienestar y el honor de nuestra patria $[\ldots]^{14}[\ldots]$ mi razón [...] no acertando a resistir la evidencia de los hechos, después de veinte años de calamidades $y$ de miserias, se inclina a cualquier otra cosa que no sea el sistema republicano [...] pues si no ha ocasionado esas calamidades y esas desventuras, no ha podido evitarlas $[\ldots]^{15}$

Esta verdadera "profesión de fe" republicana muestra hasta qué punto, la idea combatida por él mismo de la re. pública como un credo, la idolatría de una forma de gobierno única y excelsa, se expresaba en su propio discurso.

A la manifestación de su republicanismo como sentimiento, se une su defensa de la compatibilidad de su ideario monárquico con el liberalismo; aunque sus palabras parecen más bien destinadas a demostrar el eclecticismo de lo liberal y el uso ilegítimo del liberalismo como bandera:

13 Ibid, p. 13.
14 Ibid., p. 84.
15 Ibid., p. 90. 
[...] una monarquia puede ser tan libre como una república [...] tengo derecho a no ceder a nadie en liberalismo. iEs por otra parte tan elástico el sentido de esa hermosa palabra liberal![...] liberales, se llamaron (a si propios) los hombres de la Acordada y del Parián, y liberales los que los combatieron: liberales, los que dictaron la injusta e impolítica ley de expulsión de españoles [...]; y liberales, los que, hasta lo último, la reprobaron y resistieron: liberales, los que en 838 tendieron a un enemigo extranjero, en señal de amistad, una mano que hubiera debido cortar el verdugo; y liberales, los que denodadamente resistieron a ese mismo enemigo extranjero, [...] por consiguiente, ya se ve que hay en que escoger, y que, a pesar de todo, yo puedo creerme liberal $[. . .]^{16}$

El "a pesar de todo" expresa su conciencia de que, para muchos de sus compatriotas, el monarquismo era in. compatible con el credo liberal.

El liberalismo de Gutiérrez de Estrada es antirrevolucionario y antidemocrático, como lo es el liberalismo europeo de mediados del siglo XIX. Él partió de una concepción de la revolución y del proceso revolucionario en sí, sumamente cargada de significado en la comparación con los procesos europeos, y especialmente el francés. Su modelo, expreso en toda su argumentación e implícito en los personajes que él admiraba y en las citas que reprodujo, era la revolución de 1830 en Francia. Sus elucubraciones integraron en el proceso la evolución desde 1889 , aunque sin duda no compartía mucho de esa primera etapa. Su idea era que una vez concluida la obra de

\footnotetext{
16 Ibid., pp. 91-92.
}

destrucción había que comenzar la obra de reparación, la de perseverancia, con cordura, tino, sabiduría y firmeza. Los ejemplos de hombres apro. piados para esta labor son Casimir Perrier y Thiers; la revolución era un proceso político acabado.

La aplicación en la paz de los beneficios de la revolución: eso era lo que México no había logrado. La paz era lo único que garantizaría la prosperidad, con un gobierno que debía dar seguridad sin atacar ni directa ni indirectamente a las personas, las propiedades "ni las bases más esenciales de la moral y la prosperidad pública". El respeto de las libertades civiles, la garantía de la seguridad, de la libertad de imprenta, ése era el marco del liberalismo de Gutiérrez de Estrada. Y a partir de estas ideas políticas hay que interpretar su ataque contra la expulsión de los españoles, contra la anarquía y los excesos de la república, y no en el marco de un simple conservadurismo, aunque éste también estuviese presente en su fuerte ligazón a la comunidad española. La crítica a la expulsión de los españoles apunta al respeto de los derechos individuales y la garantía de la propiedad.

Sus ideas antidemocráticas aparecen claramente en la idea de una Convención de ilustrados, que analizaremos más adelante, y en su idea del papel del pueblo. En su paternalismo expresado en estas líneas como una de sus preocupaciones, el triunfo del espíritu de facción que es compañero inseparable de los gobiernos débiles o demagogos los cuales no son capaces de frenar esta permanente vocación de inestabilidad, la participación del 
pueblo aparece como objeto y no como sujeto del gobierno. Es notorio cómo distingue entre el "pueblo" y los "partidos", el primero como dócil y fácil de gobernar, los segundos, como responsables de la anarquía. ${ }^{17}$

[...] por su docilidad y templanza es el más fácil de gobernar de todos los pueblos del mundo $[\ldots]$ bastaria un gobierno capaz, por su energía de mantener a raya a los ambiciosos agentes de turbaciones, que lo instigan y arrastran algu. na vez, a culpables excesos $[\ldots]^{18}$

Su discurso, más que reaccionario es por el contrario progresista en los términos de su siglo. Si los partidarios de la República eran revolucionarios como lo habían sido los franceses del XVIII, Gutiérrez de Estrada ingresa en la cultura política del liberalismo del siglo XIX en pleno: orden y progreso.

En su análisis de la república en Francia y en Estados Unidos hay un enfoque que lo distingue de gran parte de los representantes del liberalismo mexicano, y es su escepticismo con respecto al poder transformador de las leyes y las constituciones para hacer variar las costumbres y los hábitos de un pueblo:

[...] ¿habrá quien sostenga que porque en lugar de un virrey hemos tenido presidentes, entre los cuales no ha faltado alguno que ni leer ni escribir supiese, nos convertirmos ipso facto en verdaderos republicanos? [...] $]^{19}$

17 Ibid., p. 32

18 Ibid., p. 64.

19 Ibid., p. 44.
En el caso de Francia, a pesar de la revolución, de haber terminado con el influjo del clero y la nobleza, de haber distribuido la propiedad; a pesar de que Napoleón organizó la administración pública, de su moralidad social, etc., no había podido instaurarse una república. El caso de Estados Unidos era diferente, allí las leyes no hicieron más que declarar un hecho que ya existía.

Sin embargo, él mismo propone una solución formal. La monarquía sal. vará a México de la disolución social, de la fragmentación territorial, de la conquista extranjera. Su confianza en las leyes se inscribe más en la idea del orden, la seguridad, la prosperidad que en la de las leyes transformadoras de la sociedad.

Incluso la idea tan reiterada de la "inexistencia de hombres capaces que gobiernen", pierde todo sustento al confrontarla con sus propias palabras. Hablando del progreso material y de la estabilidad de las monarquías europeas dice:

[...] no todos tienen gobiernos constitucionales, justos, sabios y benéficos, ni hombres de energía y probidad generosamente consagrados a hacer felices a sus pueblos; porque para moderar el excesivo fervor patriótico de tales hombres, está siempre expedita la acción saludable de las leyes, protectoras de la seguridad del Estado, y de las personas y propiedades de los particulares. Por eso [...] todos tienen paz; base precisa, e indispensable condicion de la felicidad de los pueblos; y por consiguiente todos ellos prosperan $[\ldots]^{20}$

${ }^{20}$ Ibid., p. 23. 
El discurso superficial de "los hombres" cae bajo el peso del argumento primordial que es sin duda el de las leyes protectoras de las libertades civiles, la seguridad y el orden.

\section{EL LIBERALISMO ORGÁNICO. LA DEFENSA DE LA MONARQUÍA}

Cara a cara con el fracaso de la república ¿cuál es la solución que presenta Gutiérrez de Estrada? La libertad no es patrimonio exclusivo de los regímenes republicanos. ¿Qué es lo que se pretende de un gobierno liberal? Que tenga una base legal, una constitución que contenga los derechos individuales del ciudada. no, los derechos civiles que hacen la seguridad del ciudadano en su vida y en sus bienes, la igualdad ante la ley, la libertad de expresión. Cierta participación del "pueblo" a través de sus repre. sentantes: un parlamento. División de poderes, poder legislativo en cámaras, poder judicial independiente. Fomento de las condiciones que permitan la prosperidad individual y la de la nación. Todo ello estaba presente en las monarquías que él conocía, en la Francia y en la Inglaterra de 1840. Pero no existen formas de gobierno ideales sino la forma adecuada para cada nación en determinado momento. ¿Qué contradicción existía entre monarquía y liberalismo, entre monarquía y libertad? Una vez dilucidado esto, ¿cuáles eran las ventajas del sistema republicano si hasta entonces sólo se había experimentado la anarquía, y estaba siempre latente el peligro del avance extranjero?

Partiendo del concepto de la organicidad de una forma de gobierno, de su adecuación a la sociedad, el discurso de Gutiérrez de Estrada se centrará en dos puntos: demostrar que la monarquía no era sinónimo de despotismo y mostrar sus ventajas con respecto a la estabilidad y prosperidad en lo interior y la seguridad en lo exterior.

Gutiérrez discute el hecho, que sería tan notorio en el discurso de la reacción a su carta, de que la república se consideraba un axioma incuestionable. Una forma de gobierno debe ser acorde con las costumbres, las tradiciones, "el orden de las cosas" del país que rige. El gobierno republicano re quiere de cierta ejercitación, educación en sus principios y conducta; no se puede saltar de golpe del despotis. mo a la república. Alude a la tradición colonial: México ha sido gobernado monárquicamente desde la conquista, legislación, instituciones, costum. bres, "todo en México es monárquico". El error de la A mérica española ha sido la adopción de sistemas políticos que no le convienen:

[...] querer saltar de un golpe desde el abismo del más abyecto despotismo hasta el grado más culminante dè la libertad política, es pretender que un re cien nacido ejerza repentinamente las facultades de un robusto gigante [...] Si en algo se debe caminar por grados, es en el dificil intento de perfeccionar las instituciones sociales de un pueblo $[\ldots]^{21}$

La crítica al afán de perfectibilidad social a través de las leyes y a contrape-

${ }^{21}$ Ibid., p. 39. Nótese que al referirse al dominio español como un "abyecto despotismo" la visión de la colonia no se inscribe en el pensa. miento conservador. 
lo de la sociedad, constituye la línea divisoria entre Gutiérrez de Estrada y el resto de los liberales mexicanos. Afirmaba que él mismo proclamaría la república, si supiese que podía aplicarse; pero como no era así proponía un "ensayo", así lo calificaba, de "verdadera monarquía en la persona de un príncipe extranjero". Una convención debería discutir una nueva forma de gobierno de acuerdo con las circunstancias. En ella no deberían reflejarse ninguno de estos partidos ya que se reproducirían las causas que habían provocado los males de la nación, por lo mismo el Congreso existente no podía ser un órgano válido para tal fin. La convención era concebida como una vuelta de la nación a la sociedad natural.

[...] porque es político y justo apelar a la sociedad misma cuando se ventila un objeto que tanto le interesa a ella toda entera; y cuando se trata de formar un nuevo código fundamental, un nuevo pacto de alianza que todos deben acatar igualmente, no se presenta otro camino más obvio que recurrir a un congreso elegido para este caso especial, con el carácter de constituyente o de convención $[\ldots]^{22}$

El pacto social se expresa en la Constitución que es la que fundamenta la forma de gobierno; si se pretende cambiar ésta el pacto debe ser reformulado y para ello volver a la sociedad natural, que él entendía como una sociedad libre de la acción de partidos, lo que es una de las grandes utopías de su plan. ¿Cuál se supone que sea la base

22 Ibid., p. 11. social de este proyecto? Su discurso iba dirigido a la elite ilustrada del gobierno y de la nación en general; he aquí otro componente antidemocrático de su discurso. La composición de la convención debía surgir de elecciones cuya libertad el gobierno debía proteger, pero al mismo tiempo, éste debía evitar que en ellas tuvieran influencia los partidos. Gutiérrez de Estrada hacía un llamado a la elite ilustrada, con lo que el concepto de sociedad natural y el carácter popular de esa convención tenía un alcance muy restringido. Su solución era elitista. Se trataba sin duda de una elite aristocrática que no participaba en la lucha política de esos años. ${ }^{23}$

Gutiérrez de Estrada proponía una monarquía democrática. Criticando el discurso de Tornel en donde éste afirmaba preferir "una tormentosa libertad al quietismo sepulcral de la ominosa servidumbre ${ }^{n},{ }^{24}$ él contestó que esos dos escollos no se podían evitar, ni con un gobierno puramente republicano, ni con una monarquía absoluta. Fue entonces cuando habló de la grandiosa invención de la época, los gobiernos mixtos en los que el pueblo realizaba todos los actos que podía ejercer en su totalidad y se despojaba de las facultades que podían perjudicarlo. ${ }^{25}$

Su argumento era que "una monarquía puede ser moderada y democráti. ca, como despótica y arbitraria una re-

23 Ibid., pp. 15-16.

24 Tornel y Mendívil, Discurso, 1840, p. 12. Centro de Estudios de Historia de México (Condumex), fondo xu-I, carpeta 24 , documento 1894.

25 Gutiérrez Estrada, Carta, op. ctt., p. 67. 
pública $[\ldots]^{26}$ Si en un régimen republicano, como tantas veces había pasado en México, el presidente estaba por encima de la Constitución, y ya que la tiranía era un mal en sí y no por la cantidad de personas que lo ejercieran, ¿no sería mejor experimentar una monarquía regida constitucionalmente ${ }^{27}$

Los dos grandes peligros que atentaban contra la nación y que requerían del establecimiento de la monarquía para su salvación eran la disolución interna y la amenaza extranjera.

Mostraba la situación interna de México como un círculo vicioso. La libertad sin limitaciones tendía a ensancharse y llevaba a la anarquía, y ésta a la dictadura. La división de la nación por la existencia de dos partidos de igual fuerza, lo que impide que uno triunfe sobre el otro, haría que la lucha fuera permanente. Un monarca con el poder capaz de dirimir la competencia entre los dos partidos, podría formar entre los dos uno solo verdaderamente nacional y acabar con la disolución. Una nueva constitución debía fundar

un gobierno capaz de vencer todas las resistencias que se opongan a la ejecu. ción de la ley; que imprima con su jus. tificación, imparcialidad y energía aquel respeto que hace amar la obe. diencia ordenada por la ley; que sea bastante fuerte a contener dentro de sus límites a todas las autoridades secundarias, siempre propensas a ensancharlos o a traspasarlos; que reprima las pasiones que sean contrarias al bien general: y finalmente, que vigile con

26 Ibid., p. 91.

${ }^{27}$ Ibid., pp. 49-50. infatigable solicitud sobre todas las partes que constituyen el orden público $[\ldots]^{\prime 28}$

Con respecto a la amenaza extranjera lo que más asustaba a Gutiérrez de Estrada era la amenaza norteamericana y la veía en términos de una lucha entre la "raza anglosajona" y la "nacionalidad". No sólo la integridad territorial estaba en juego sino la nacionalidad entendida con base en la tradición cultural y la religión. Él puso tonos dramáticos al avance norteamericano, y situó su discurso al nivel de la dicotomía, como lo harían también sus críticos:

Si no variamos de conducta, quizá no pasaran veinte años sin que veamos tremolar la bandera de las estrellas nortea. mericanas en nuestro palacio nacional; y sin que se vea celebrar en la espléndida catedral de México el oficio protestante! $[\ldots]^{29}$

Veía el asunto de Texas como el primer paso de una estrategia norteamericana destinada a ir disgregando el territorio mexicano. La "república" aparece en sus palabras como una ideología subversiva, un instrumento en manos del extranjero:

[...] Un invasor, que no ha emprendido militarmente la conquista de nuestro territorio, sino enredándonos en los lazos de ciertos principios políticos, tan mortales para nosotros, como llenos de vida $y$ de fuerza para ellos $[\ldots]^{30}$

\footnotetext{
28 Ibid., p. 43.

29 lbid., pp. $57-58$.

${ }^{30}$ Ibid., p. 59.
} 
El tema clave del monarquismo mexicano es la persona que rija el gobierno monárquico en México, ya que la legitimidad de una monarquía depende de la persona que ocupe el trono. Esa persona, decía, debía ser extranjera para impedir que se repitiera lo de Iturbide "cuando un mexicano, ilustre por su hechos militares, y no más, la gobernó con el carácter de emperador $^{n} .31$

Independencia y monarquía con príncipe extranjero no eran incompatibles, afirmaba y citaba casos europeos de naciones que coronaron príncipes extranjeros, y se preguntaba si la nación mexicana entendió perder la independencia " $[\ldots]$ cuando precisamente al proclamar la suya, ofreció la corona a un rey, y rey extranjero, pues extranjero fue para nosotros el monarca español desde que don Agustín de Iturbide proclamó aquella misma independencia? [...]"32

La amenaza norteamericana sellaría la propuesta de Gutiérrez de Estrada con carácter de urgente, la independencia estaba "inminentemente amenazada por nuestros codiciosos vecinos". ${ }^{33}$ Era preferible entonces aceptar el gobierno de un monarca constitucional aunque fuera extranjero.

\section{EL "DEBATE" QUE NO FUE}

El "debate" periodístico que se desató desde el 2 de septiembre, entre Gutiérrez, el gobierno y El Censor de Vera-

31 Ibtd., p. 37

32 Ibid., p. 69

33 Ibid., p. 85. cruz se generalizó a "toda la prensa" desde el 21 de octubre, apareciendo los últimos editoriales y artículos del tema a comienzos de diciembre, aunque el furor de la reacción se agotó en noviembre.

La reacción a la carta de Gutiérrez de Estrada no fue espontánea, por lo menos no desde el momento en que el gobierno actuó. El Mosquito fue el único diario, según la referencia que se tiene por el Diario de Gobierno y las informaciones oficiales, que habría apoyado el proyecto de Gutiérrez; su editor, el capitán Francisco Berrospé, fue encarcelado junto con Cumplido. El Diario de Gobierno se pronunció contra la carta calificándola como folleto subversivo. Puesta fuera de la le. galidad la propuesta, el debate periodístico no podía ser libre. La posible minoría que era favorable al proyecto no pudo expresarse.

\section{LA "INDIGNACIÓN UNIVERSAL"}

En un Remitido del 2 de septiembre, Gutiérrez de Estrada defendió la figura de Bustamante como presidente, criticó a la oposición y previno contra los peligros de la instauración de una dictadura, tanto más negativa cuanto que no existía la persona que pudiera llevarla a cabo. ${ }^{34}$ El Censor de Veracruz encabezaría la respuesta de la oposición defendiendo la figura de Santa Anna, a la que aludía Gutiérrez de Estrada como el candidato idóneo para

\footnotetext{
34 "Remitido" de Gutiérrez de Estrada, Diario de Gobierno, 2 de septiembre de 1840.
} 
dirigir la dictadura, y acusando a éste de querer satisfacer rencores personales. Se referían a él como un "pasado por agua", o sea el mexicano que habiendo viajado a Europa, a veces a cos. ta de la república, no encontraba más que vicios y defectos en su país. También atacaban su petulancia y evidentemente tomaban como elemento, fuerte en el desprestigio de su imagen, esta visión de él como un aristócrata europeizante que despreciaba a su país, como un "petimetre acicalado".

En un artículo que apareció en $E l$ Cosmopolita, firmado por "Un mexicano", un verdadero panegírico de Santa Anna, se hablaba de Gutiérrez de Estrada como "el viajero de cuatro años", se criticaba su petulancia en mostrar sus viajes e instrucción, su "charlatanismo insufrible" y su "odio a la patria". ${ }^{35} \mathrm{El}$ marco de los escritos de esta primera reacción, fue el de la defensa de los santannistas contra los ataques de Gutiérrez.

El 18 de octubre salió a la luz la carta de Gutiérrez de Estrada. La respuesta de la reacción apareció en los diarios a partir del día 21, y giró en torno a algunos supuestos y argumentaciones básicas. En primer lugar, la identificación de monarquía con despotismo y pérdida de independencia. O sea la incompatibilidad entre forma monárquica de gobierno y práctica de las libertades. La contrapartida de este supuesto era, desde luego, la identificación de libertad y república. La legitimidad de la república se fundamentaría en su base popular, es decir, en el hecho de

35 "Comunicado firmado por 'Un mexicano'", El Cosmopolita, 21 de octubre de 1840. haber sido elegida espontáneamente por el pueblo. En función de estos supuestos, la propuesta del proyecto monárquico se calificó de acto de traición o, en el mejor de los casos, de terrible equivocación.

Las críticas más profundas a la propuesta monárquica se centraban en tres problemas esenciales: libertad, independencia y legitimidad, y uno, diríamos, operativo, el problema del tránsito.

La identificación absoluta entre libertad y república, esclavitud y monarquía no es sólo un recurso discursivo empleado en la polémica, sino uno de los componentes esenciales del pensamiento pro republicano de estas primeras décadas del siglo XIX. "Seguiremos voltejeando entre nuestras revueltas políticas; pero somos libres y no queremos volver a ser esclavos [...]. ${ }^{36} \mathrm{La}$ identificación iba más allá de los conceptos y se aplicaba a su per-sona, haciéndolo aparecer como aliadoy servidor del despotismo. " $[$...] hijo desnaturalizado, que en un momento de delirio político, concibió el infame proyecto de proponer a México la idea de pedir a Europa un amo que nos ven. ga a esclavizar a su placer $[\ldots]^{n 37}$

Las argumentaciones más exitosas de la oposición a su propuesta se centraron en sus ideas sobre los vicios, defectos e inexperiencia de la clase política mexicana. Si en una monarquía moderada los ciudadanos disfrutaban de tantas libertades como en la repú-

36 "Comunicado", El Cosmopolita, 11 de noviembre de 1840 , p. 1.

${ }^{37}$ La Gazeta de Zacatecas del 29 de octubre; Diario de Gobierno, 9 de noviembre de 1840 , p. 2. 


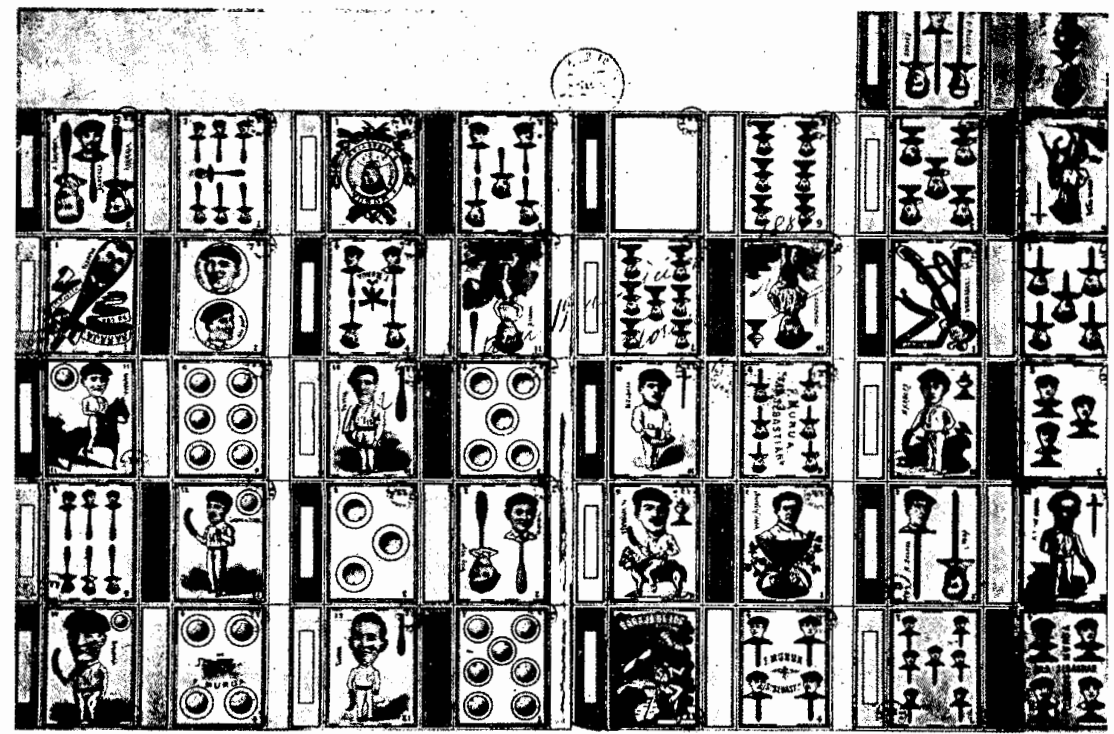

blica, si se tratara de una monarquía representativa,

[...] había de dar a los mexicanos la formación de sus leyes, la administración de justicia, el mando de su ejército, la dirección oadministración de hacienda, y con hombres tan incapaces como supone el señor Estrada a sus paisanos o ese monarca extranjero sólo se reduciría a ser el ejecutor de esas leyes impremeditadas y perjudiciales, o tenía que sobreponerse, y establecer desde un principio un gobierno absoluto y despótico, que sólo al cabo de muchos siglos podría presentar esas ventajas y esa libertad in. dividual de que no gozan los vasallos del sultán de Constantinopla, o del emperador de China, o de Rusia[... ${ }^{38}$

38 Editorial, Diario de Gobierno, 22 de octubre de 1840 .
El otro pilar básico del rechazo al proyecto de Gutiérrez de Estrada fue la identificación de "monarquía con príncipe extranjero", con "dominación extranjera" o, que es lo mismo, la incompatibilidad entre independencia y monarquía. Los periodistas tergiversaron la imagen de una monarquía constitucional al decir que su proyecto era " $[. .$.$] que se establezca en el país$ una constitución monárquica, y con ella un príncipe extranjero que lo gobierne a su voluntad [... $]^{n 39}$

Se hacía alusión a la inexistencia de una antigua nobleza, a la pobreza del erario para afrontar los gastos de una

39 La Gazeta de Zacatecas de 29 de octubre, Diario de Gobterno, 9 de noviembre de 1840 , p. 2. 
monarquía y al hecho de que el príncipe extranjero vendría con nobles y ejército de su país.

¿El trono descansaría sobre una nobleza de nuevo cuño, improvisada, entre los mexicanos o se trasplantaría con el real vástago del otro lado de los mares? [...] y una nobleza nueva nunca sería otra cosa que una verdadera farsa [...] la nobleza que se creara sería mucho más inepta para la monarquía que puede serlo la clase media de nuestro pueblo, para los cargos periódicos de la república $[\ldots]^{40}$

Una nobleza sin legitimidad no sería más eficiente ni más honrada en la monarquía, que la clase media, reconocida aquí como la clase dirigente de la república.

Se recurría a la historia glorificando las luchas por la independencia, y entendiendo el establecimiento de una monarquía como la invalidación de los sacrificios de la patria, recurso que usarán del mismo modo con la defensa de la república. Esto es significativo porque, tanto la independencia como la república, aparecían como los conceptos fundantes de la nación, lo cual tenía un sentido histórico en el caso de la independencia, pero no en el de la república. La forma republicana como esencial a la nación mexicana no era, entonces, una invención del republicanismo posterior a Ayutla sino que estaba presente ya en este momento.

Los Hidalgos, Morelos, Iturbides, nos dejaron trazado el camino de honor y la virtud $[. .$.$] patenticemos al mundo que$

$40 \mathrm{El} \mathrm{Conciliador} \mathrm{de} \mathrm{Jalapa,} \mathrm{octubre} \mathrm{30;} \mathrm{El}$ Cosmopolita, 7 de noviembre de 1840 . hemos sabido legar a nuevos hijos intacta y sin mancilla, la rica herencia que nos compraron con sus vidas los primeros padres de la Independencia $[\ldots]^{41}$

Optar por la monarquía era volver a la colonia y perder la nacionalidad: México tendría que retroceder al estado de colonia, del que partió para ser na. ción. ${ }^{42}$ El proyecto de Gutiérrez de Estrada era calificado de "[...] idea tan innacional como contraria a la independencia del país $[\ldots]^{n 43}$

Con respecto a la amenaza extranje$\mathrm{ra}$, se pensaba que la monarquía no era la solución, por el contrario la amenaza de la "república libre del norte" se. ría mayor en la medida en que el amor por las instituciones republicanas haría crecer los deseos de incorporación a la democracia del norte. ${ }^{44}$

El problema central que se oponía a la propuesta de Gutiérrez de Estrada, y que sin duda era el verdadero obstáculo para la implantación de la monarquía, era el de su legitimidad. Para el pensamiento liberal mexicano de mediados del siglo XIX, la nacionalidad tenía su origen en la independencia. El problema para la instauración del régimen monárquico era que la tradición en la que se apoyaba era aquella con la que se había roto para formar la na-

41 Sesión de la Junta departamental de Guanajuato del 31 de octubre; El Cosmopolita, 7 de noviembre de 1840.

42 El Conciliador de Jalapa del 30 de octubre; Diario de Gobierno, 5 de noviembre de 1840.

${ }_{3}$ Editorial, Diario de Gobierno, 8 de noviembre.

${ }^{44}$ El Conciliador de Jalapa del 30 de octubre; Diarto de Gobierno, 5 de noviembre de 1840. 
ción. Ésta era la contradicción fundamental que estaba en la base de la imposibilidad de establecer la monarquía. Su momento de realización fue Iguala. Entonces, realizarla significaba hacer una síntesis, concretar una independencia aceptada por la ex metrópoli, verter, en un molde nacional, la sustancia de la tradición colonial y formar así el nuevo país. Pero en 1840 , se decía: "¿Qué poder, qué representación tendría un príncipe aparecido de repente entre nosotros [...]?"45

Se cuestionaba también la metodología del tránsito. No prevista por la constitución, el cambio de forma de gobierno necesitaría de una revolución para concretarse, además ¿quiénes compondrían la convención? Habría "algunos monárquicos decididos", sin embargo su número e influencia no podrian compararse con los otros partidos que se han dividido la república por dieciséis años. ${ }^{46}$

Significativa por el papel que cumplieron los santannistas en el rechazo de la propuesta de Gutiérrez, la carta de Santa Anna a Almonte insistía en los tópicos generales. Luego de calificar el proyecto de Estrada como criminal y monstruoso y de aludir una vez más, a sus sacrificios por el país Santa Anna dice:

me parece preferible la ruina de todos los mexicanos entre los escombros de la república, al vasallaje bajo un monarca extranjero; y quién para ser su siervo cambiará el honor de haber derramado su sangre por la independencia, ni el

45 Diario de Gobierno, 27 de octubre de 1840.

46 Diario de Gobierno, 22 de octubre de 1840.

LA MONARQUÍA EN MÉXICO noble orgullo de haber proclamado el primero la república en Veracruz el 12 de diciembre de $1822[\ldots]^{47}$

Otra vez se plasmaba aquí la idea de la república como esencia de la nación, llevada al extremo de la dicotomía "república o muerte", tan recurrente en los discursos políticos e ideológicos en que un partido, una forma de gobierno, una religión o una empresa determinada era concebida como el ser mismo de la nacionalidad.

La solución para los problemas de la nación estaban dentro de la misma república, mejorando sus instituciones y con la experiencia de la práctica política; el tiempo cumplía un papel fundamental en el discurso republicano del siglo XIX.

Reformemos nuestras instituciones, haya paz, orden, libertad y protección al trabajo y a la industria; para que las costumbres se purifiquen y para que el árbol de la independencia dé sazonados frutos $[\ldots]^{48}$

Toda la reacción coincidía en que el proyecto lanzado por Gutiérrez de Estrada había servido como elemento de unión en el país al demostrar que, si había acuerdo en algo era precisamente en la forma republicana de gobierno. La asociación de república con independencia revestía, al movimiento de rechazo a la monarquía, con el papel de defensor de la nacionalidad y la unión del país.

47 "Carta de Santa Anna a Almonte", 31 de octubre de 1840, Biblioteca Nacional, LA F. 352.

48 Diarto de Gobierno, 5 de noviembre de 1840; El Conciliador de Jalapa del 30 de octubre, p. 2. 


\section{LA REACCIÓN DEL GOBIERNO}

La oposición acusó al gobierno de no haber respondido con la rapidez nece. saria a la publicación del folleto. Éste se había anunciado con grandes carteles desde la mañana del 18 , cuando se pusieron a la venta los ejemplares, y el gobierno trató el tema en la Cámara de Diputados. En la mañana del 21 se recogieron los ejemplares que no habian sido vendidos. El Diario de Gobierno consideró subversivo el folleto. El 23, 24 y 25 de octubre se sucedieron las proclamas de Bustamante, Valencia y Almonte.

Bustamante lanzó una proclama al ejército en la que calificaba al escrito de Gutiérrez de Estrada como un "[...] impreso subversivo y sedicioso en primer grado, que justamente ha escitado una general indignación en esta capital, llamando a la vez seriamente la atención de las augustas cámaras y del gobierno[...]" El gobierno pretendía quedar libre de toda sospecha sobre su participación en el proyecto monár. quico, sobre todo a partir de la indig. nación que había suscitado en los medios periodísticos, "[...] evitar los extravios de la opinión y las interpretaciones malignas a que pudiera dar lugar a los enemigos del orden la lectu. ra del impreso [...]" 49

El presidente se mostraría sorprendido por la actitud de Gutiérrez, sobre todo después de que éste manifestó su fe republicana antes de viajar a Europa, $y$, considerando que

49 "Proclama de Bustamante dirigida a los militares", 23 de octubre, publicada en el Diario de gobterno del 30 de octubre.
[...] semejantes publicaciones, como la erección de un nuevo estandarte, levantado para el fomento de la guerra civil [...] y porlo mismo muy perjudiciales a la tranquilidad interior, no menos que a la independencia y dignidad nacional $[\ldots]^{50}$

Hizo un llamamiento a los soldados, conjurándolos en nombre de la patria a perecer antes que permitir la dominación extranjera. ${ }^{51}$

La carta de Gabriel Valencia era mucho más agresiva ya que acusaba a Gutiérrez de estar en connivencia con las cortes europeas para someter a México a una dinastía extranjera y añadia que la publicación del folleto tuvo la intención de probar cómo reaccionaba la administración actual y la clase militar. 52

Los argumentos contra el proyecto de parte de los diferentes ámbitos del gobierno eran similares. La actitud general, sobre todo la de Bustamante, im. plicado desde el momento en que la carta iba dirigida a él, fue demostrar que no tenían nada que ver con la propuesta de Gutiérrez.

\section{LOS DE AFUERA NO SON DE PALO}

Los testimonios de algunos observadores europeos del conflicto, muestran una reacción diferente. Dos periódicos cuyos redactores eran extranjeros se ocuparon del asunto: Le Courrier des deux mondes y La Hesperia.

50 Ibid.

51 Ibid.

52 "Carta de Gabriel Valencia al presidente", México, 22 de octubre de 1840, publicada en el Diario de Gobierno del 24 de octubre y en $E t$ Cosmopoltta del dia 28. 
En los artículos de Le Courrier des deux mondes se hacía alusión a Gutiérrez de Estrada como un liberal ilustrado, de experiencia administrativa y honestidad a toda prueba. Las críticas a su proyecto se centraban en dos aspectos: por un lado, en la juventud del gobierno y de la nación mexicana; y en la nacionalidad, como un sistema regular de gobierno y la fortuna pública que, decían, no se fundan en veinte años. La propuesta de establecer una monarquía extranjera no era entonces un crimen sino un error. En este sentido planteaban fundamentalmente el problema de la persona que debía ocupar el trono.

Criticaban a la oposición por su falta de tolerancia y de ejercicio del liberalismo que predicaban. ${ }^{53}$ Llamaban la atención sobre la trascendencia de este evento que dominó completamente la atención pública, y se asombraban de la indignación con que se había recibido la noticia. Decía Hypolite Thivol que la prensa creía ver en el centro de la ciudad de México al pretendiente al trono; al ejército alarmado por sus jefes que mostraban a la monarquía lista para devorar las libertades y la independencia nacionales; a las cámaras votando con urgencia medidas para cortar el mal de raiz. ¿Contra qué tanta exaltación?, se preguntaba el autor, y contestando a esta pregunta, definía el proyecto de Gutiérrez: "Contra cuatro líneas de utopías. [...] Contra una sombra fan-

53 Extracto de periódicos presentados por Gutiérrez de Estrada, sin portada, p. 9, traducido del Courrier des deux mondes, $\mathrm{e}$ inserto en el núm. 91 de El Mosquito, Biblioteca Nacional, LAF. 352. tasmagórica que aparece y desaparece $[. . .]^{\text {"54 }}$

Su opinión era que la desproporción de la indignación general había sido una forma de utilizar la impruden. cia de Gutiérrez de Estrada para atacar al gobierno, al menos ese sería el caso de El Cosmopolita que pretendía involucrar al gobierno en la supuesta conspiración monárquica. Por otra parte el escándalo provocado por el solo nombre de la monarquía demostraría la fragilidad del sistema republicano; de haber un sentimiento republicano generalizado, el silencio hubiese sido la reacción normal.

Respondiendo a un discurso patriótico de Tornel en el que éste, partiendo de la comparación entre México y Francia, concluía la imposibilidad de establecer una monarquía en México, Thivol hacía una defensa de la monarquía como forma liberal de gobierno. Todo esto servía desde luego para apoyar a Gutiérrez de Estrada frente a las ideas de Tornel y echar abajo los obstáculos que pudiera tener el establecimiento de una monarquía en México.

Una lectura similar de la situación es la que hacía el periódico La Hesperia, el 3 de noviembre de 1840 . A través de una alegoría titulada "Mi patrona y yo", en el estilo clásico de la discusión entre el ama y la criada, denunciaba la reacción desproporcionada del gobierno y dejaba caer sospechas sobre la función de éste como principal difusor del proyecto. La dueña de una casa de huéspedes

54 Ibtd., p. 12, Courrier des Detux Mondes, 31 de octubre, Biblioteca Nacional, LAF. 352. 
armaba un gran alboroto porque uno de sus hijos había osado decir que necesitaba un ama de llaves porque la casa estaba muy desordenada. Preguntando la criada a su ama sobre el porqué de tanto escándalo tratándose de una propuesta inofensiva, el ama contestaba que "[...] no son para el ama de llaves, sino para el que tenga el atrevimiento, como mi hijo, de decir, que conviene un ama de llaves para arreglar la posada [...]"55 La alegoría terminaba cuando la patrona sa. lía al balcón a preguntar a todo el mundo si no había visto por ahí un ama de llaves en dirección a la posada.

Otro extranjero que se ocupó del asunto fue Pakenham, quien dedicó una carta completa al asunto de Gutiérrez de Estrada, y fue el único que se pronunció explícitamente a favor del proyecto.

Siento la obligación de ser honesto al confesarle que tengo, desde hace tiem. po la opinión ahora expresada por el señor Gutiérrez así como la completa desesperanza respecto de cualquier mejora en el estado de este país bajo la actual forma de gobierno; y estoy convencido que, aunque no se atreven a hacerlo público, el noventa por ciento de los mexicanos que tienen algo que perder están en la misma línea de pensamiento $[\ldots]^{56}$

Es interesante la idea de Pakenham de que el $90 \%$ de los mexicanos que

55 Ibid., p. 19, La Hesperia, México, 3 de noviembre, Biblioteca Nacional, I.AF. 352.

56 "Carta de Pakenham", 26 de octubre, 1840 , El Colegio de México, Informes Consulares: Fo50/138. F. O. "tienen algo que perder" estarian de acuerdo con la idea monárquica. Exageración aparte, es muy probable que existiera, entre los grupos económicos más poderosos, cierta simpatía hacia el establecimiento de una monarquía.

Negaba la posibilidad de que Gutiérrez de Estrada estuviera en connivencia con gobiernos europeos, habría actuado por convicción aunque quizás movido por el ejemplo de lo que había observado en Europa. También hacía su apreciación respecto del efecto que había producido la carta en la opinión pública: "La indignación, menos real estoy convencido que afectada, con la que la proposición ha sido recibida ha forzado al gobierno a tomar medidas activas para la persecución del ofensor." 57

En este último grupo de opiniones vemos que es una constante considerar la desproporción de la reacción generalizada frente al escrito de Gutié. rrez, y la indignación por la falta de respeto a la libertad de expresión. Mientras que las críticas, en el caso de hacerse, se concentraron en la posibi. lidad de aplicación de la monarquía, sobre todo por el problema de la persona que debía ocupar el trono: el problema de la legitimidad.

El rechazo al proyecto de Gutiérrez de Estrada sugiere que realmente existía un sentimiento antimonárquico en México, aunque esta antipatía, si bien generalizada, no era "universal". En los círculos aristocráticos, tanto los europeizados a la francesa, como los respetuosos de la cultura hispánica, en los

57 Ibid. 
sectores comerciantes no involucrados en la política del momento, y en parte de la clase política, esta idea no debió ser tan repugnante.

Sin duda la reacción fue desproporcionada sin siquiera entrar en la discusión del ataque a la libertad de prensa fundado en una supuesta afrenta a la nacionalidad. El hecho de que la carta fuera enviada al presidente, aunque ésta no contenía la propuesta monárqui$\mathrm{ca}$, fue determinante: hacía aparecer al gobierno como respaldando la acción de Gutiérrez de Estrada lo que volvía la propuesta más escandalosa, y fue esto lo que obligó al gobierno a cargar las tintas en cuanto a denostar la idea y perseguir a Gutiérrez.

Las respuestas de los diarios del interior, salvo Veracruz, tienen el sentido de hacer profesión de fe republicana. Las de los medios más o menos oficialistas, de defender al gobierno de la acusación de connivencia con Gutiérrez. La posición de $\mathrm{El}$ Censor de Veracruz y de la crítica más feroz fue distinta; republicanos o no, usaron la carta para dejar malparado al gobierno y defender a Santa Anna, que, como vimos, tenía su deuda pendiente con Gutiérrez de Estrada. Y lo que de hecho le granjeó a Gutiérrez el odio general fue su crítica "univer. sal" a los dos partidos y a todo lo que había sido la vida política de México desde la Independencia. Su propuesta fue también impopular en gran medida por su cultura europeizante y su crítica feroz a la falta de cualidades de sus compatriotas para el gobierno re publicano.

LA MONAROUIÁ EN MÉXico
ALGUNAS CONCLUSIONES ACERCA DEL PENSAMIENTO DE GUTIERREZ DE ESTRADA Y DEL LIBERALISMO MONÁRQUICO AMERICANO

El pensamiento de la elite política que dirigió la revolución americana y la etapa de formación del Estado estuvo marcado por las vivencias de la guerra, y por las dificultades de organización. Es común a todas las latitudes americanas el modelo de itinerario ideológico de políticos que habiéndose iniciado con un fervor revolucionario y democrático más o menos acentuado, abandonaron este ideario frente a las circunstancias políticas y transitaron hacia posiciones más bien liberales, en los términos del siglo xIX: la paz, el orden, la prosperidad material y la limitación de la representatividad, y con ello a la implantación de gobiernos más fuertes y centralizados.

El modelo de gobierno de Gutiérrez de Estrada es la monarquía constitucional, en su variante ministerial. Sus libertades por excelencia son las libertades civiles. La defensa de la seguridad, la vida y la propiedad, es una reacción a los excesos de los procesos revolucionarios. Proscripciones, confiscaciones, persecuciones, los "horrores de la revolución" y la guerra tenían necesariamente que llevar un ansia de orden a la vez que de prosperidad, de la misma manera que la conciencia de la opresión y el despotismo, había llevado al estallido de la revolución. Ésta era la vivencia de gran parte de esta generación, era el caso en Europa, de un Tocqueville.

Gutiérrez de Estrada lejos de ser un "nostálgico del pasado", era un hom- 
bre totalmente inserto en el mundo posrevolucionario; la realidad americana y la europea, productos de sendas revoluciones, le parecen tan similares que la propuesta monárquica operando en la segunda, se le ocurre como la única salvación del país. Su posición estaba arraigada en el marco ideológico del liberalismo decimonónico con su marco feudal de reparto de la propiedad; su pensamiento no era democrático, como no lo era seguramente el de ninguno de sus contemporáneos europeos partidarios de la monarquía constitucional.

Lo de Gutiérrez de Estrada fue una escena del drama del desencuentro, que comenzó con Iturbide, en el único momento en que era posible la realización del "ser monárquico", y tuvo su acto final con Maximiliano. ${ }^{58}$

Haciendo una proyección a la esfera americana, los 24 años que separan el proyecto de la monarquía incaica de la carta de Gutiérrez de Estrada no impiden la comparación. Ambos se sitúan en un periodo posrevolucionario y ante amenaza extranjera. El sur no se había liberado aún de la acción española y no lograba la unidad; México contaba ya con la seguridad de la independencia y con un país constituido, pero tenía en cambio la amenaza de Estados Unidos. También en el sur el monarquismo fue constitucional y liberal, sin embargo, por fenómenos complejos de ideología política, los defensores del monarquismo rioplatense partieron de raíces ideológicas distintas; hubo incluso quien transitó desde Rousseau a la monarquía incaica. Mientras

\$8 O'Gorman, Supervivencta, 1969. el proyecto de Gutiérrez de Estrada era aristocrático y buscaba su legitimidad en Europa, el proyecto de la monarquía incaica fue un intento de síntesis de una tradición política europea con la legitimidad que le daba "la sanción del tiempo", y de una tradición americana con la legitimidad de la tierra y de la historia. Aun cuando la revitalización del imperio incaico vertido ahora en moldes criollos, comprendía un imperio prehispánico no democrático, la idea de los revolucionarios acerca de éste era de igualdad. La monarquía constitucional incaica tenía la ventaja de escapar a la contradicción entre independencia y monarquía de la que el caso mexicano estaba prisionero. Pero el monarquismo del sur, si bien estaba empapado del ejemplo europeo, del monarquismo constitucional del siglo XIX, rechazaba los aportes de la colonia retrotrayendo la historia a un momento previo a la conquista, volviendo a una legitimidad indígena.

Con todo, los exponentes del "liberalismo monárquico criollo" no comprendieron que la América independiente sería republicana por convicción, por imitación, y por rechazo a las estructuras de poder coloniales. El republicanismo fue la bandera de identidad de la revolución americana, frente a la Europa de la que se habían independizado, y por ello fue defendida como un credo.

\section{BIBLIOGRAFÍA}

-Documentos relativos al ingreso y a la salida de la primera Secretaría de Estado de la República Mexicana de José María 
Gutiérrez de Estrada, Ignacio Cumplido, México, 1835.

- Gutiérrez Estrada, José María, Carta dirigida al Excmo. Sr. presidente de la Re. pública sobre la necesidad de buscar en una Convención el posible remedio de los males que aquejan a la República; y opiniones del autor acerca del mismo asunto, Imprenta de Ignacio Cumplido, México, 1840.

-Hale, Charles A., El liberalismo mexicano en la época de Mora, Siglo XXI Editores, México, 1991.
-Mitre, Bartolomé, Historia de Belgrano $y$ de la Independencia Argentina, La Facultad, Buenos Aires, 1927.

-O'Gorman, Edmundo, La supervivencia política novohispana, Condumex, México, 1969.

-Tornel y Mendivil, José María, Discurso que pronuncí́ el Excmo. señor general DI.... individuo del Supremo Poder Conservador en la Alameda de la ciudad de México, en el día del solemne aniversario de la Independencia, Ignacio Cumplido, México, 1840. 


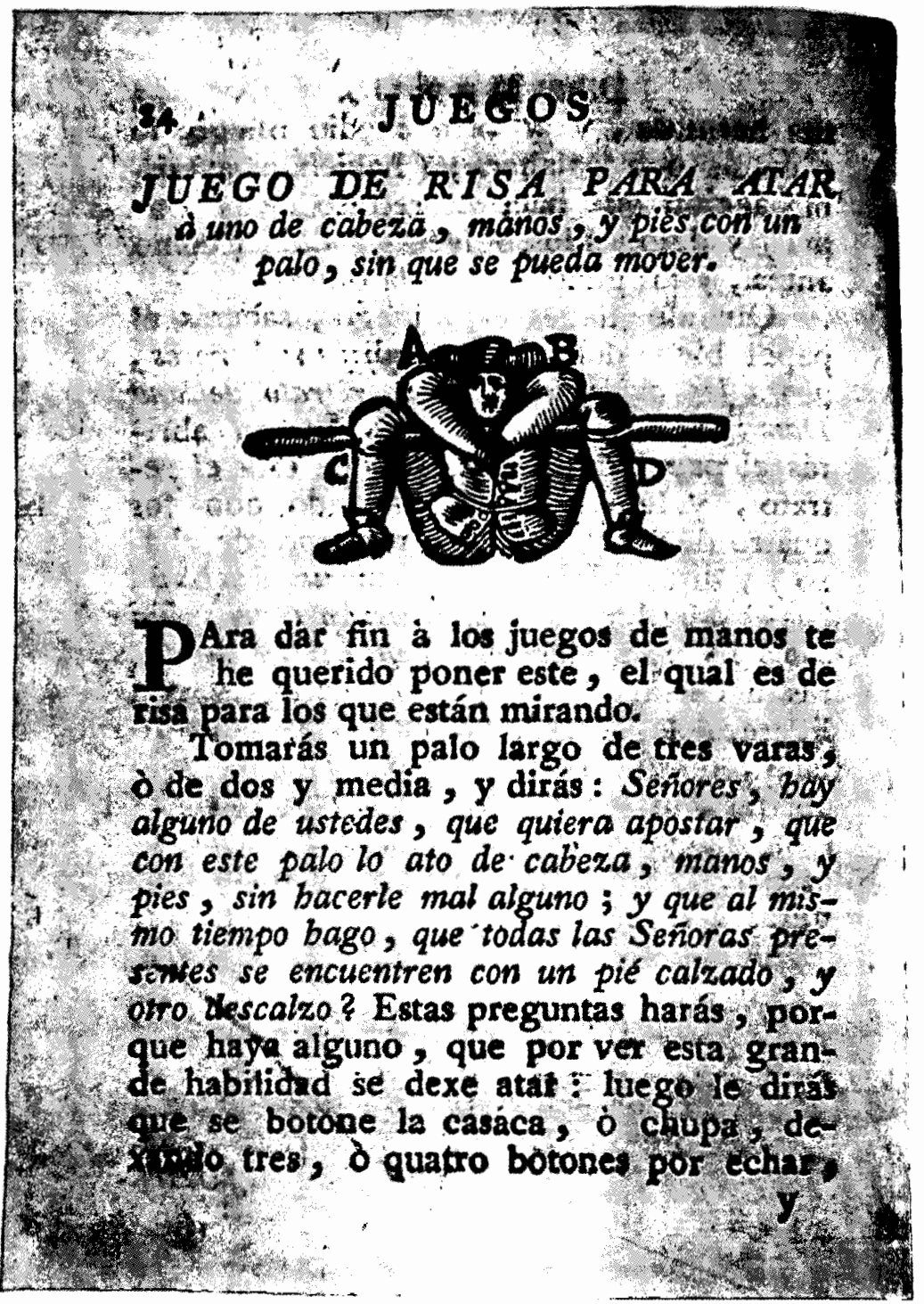

